\title{
BILANGAN STRONG RAINBOW CONNECTION PADA GRAF BEADED WHEEL
}

\author{
HAVES DERINDO, LYRA YULIANTI, SYAFRIZAL SY \\ Program Studi Magister Matematika, \\ Fakultas Matematika dan Ilmu Pengetahuan Alam, Universitas Andalas, \\ Kampus UNAND Limau Manis Padang, Indonesia, \\ email : derindoh@gmail.com, lyrayulianti@gmail.com, syafrizalsy@gmail.com
}

\begin{abstract}
Abstrak. Suatu graf dikatakan bersifat strong rainbow connected, jika untuk setiap dua titik $u$ dan $v$, lintasan rainbow antara kedua titik tersebut adalah lintasan geodesic, yaitu lintasan dengan panjang $d(u, v)$. Graf Beaded Wheel, dinotasikan dengan $B W_{2, m}$, untuk $m \geq 3$, didefinisikan sebagai suatu graf dengan $2 m+1$ titik, yang diperoleh dengan cara menambahkan satu titik pada setiap jari-jari yang ada pada graf roda $W_{m}$, untuk $m \geq 3$. Graf $B W_{3, m}$, untuk $m \geq 3$, didefinisikan dengan cara serupa, yaitu dengan menambahkan dua titik pada setiap jari-jari yang ada pada graf roda $W_{m}$, untuk $m \geq 3$. Cara menentukan bilangan strong rainbow connection untuk $B W_{2, m}$ dan $B W_{3, m}$ adalah dengan mendefinisikan pewarnaan terhadap semua sisi pada graf sedemikian sehingga graf tersebut bersifat strong rainbow connected. Untuk $m=4$, pada tulisan ini diperoleh bilangan strong rainbow connection pada graf Beaded Wheel yaitu, $\operatorname{src}\left(B W_{2,4}\right)=4$ dan $\operatorname{src}\left(B W_{3,4}\right)=5$.
\end{abstract}

Kata Kunci: Beaded Wheel, strong rainbow connection

\section{Pendahuluan}

Suatu graf $G$ didefinisikan sebagai pasangan himpunan $\left(V(G), E(G), \psi_{G}\right)$ dengan $V(G)$ himpunan titik tak kosong, $E(G)$ adalah himpunan sisi yang menghubungkan titik-titik pada $G$ dan $\psi_{G}$ merupakan suatu fungsi keterkaitan (incidency function) yang mengaitkan setiap sisi di $G$ dengan pasangan titik di $G$. Banyaknya titik di $G$ disebut orde (order) dari $G$ yang dinotasikan dengan $|V(G)|=v$, dan banyaknya sisi pada $G$ disebut ukuran (size) dari $G$ dinotasikan dengan $|E(G)|=e[4]$.

Dalam teori graf terdapat kajian mengenai teori pewarnaan, yaitu suatu bentuk kajian ilmu yang mempelajari cara mewarnai suatu graf sedemikian sehingga tidak terdapat dua titik, sisi, atau bidang bertetangga yang berwarna sama [2]. Salah satu konsep dari pewarnaan graf adalah mengenai bilangan strong rainbow connection. Konsep tentang strong rainbow connection diperkenalkan oleh Chartrand dkk. [3] pada tahun 2008. Misalkan c adalah rainbow coloring dari graf terhubung $G$. Suatu lintasan yang menghubungkan dua titik $u, v$ di $G$ didefinisikan sebagai suatu rainbow $u$-v geodesic jika lintasan tersebut mempunyai panjang $d(u, v)$, dan setiap sisi pada lintasan tersebut diwarnai berbeda. Suatu graf $G$ dikatakan strong rainbow connected jika untuk setiap dua titik $u, v$ di $G$ terdapat lintasan rainbow $u$-v geodesic. Dalam hal ini, pewarnaan $c$ dinamakan strong rainbow coloring dari graf 
terhubung $G$, sementara minimum dari banyaknya warna yang digunakan agar $G$ bersifat strong rainbow connected didefinisikan sebagai bilangan strong rainbow connection, dinotasikan $\operatorname{src}(G)$. Penelitian ini bertujuan untuk menentukan bilangan strong rainbow connection pada graf Beaded Wheel $B W_{2,4}$ dan $B W_{3,4}$. Definisi graf beaded wheel diambil dari [1].

\section{Graf Beaded Wheel $B W_{2,4}$ dan $B W_{3,4}$}

Definisi 2.1. [1] Graf Beaded Wheel $B W_{2, m}$, untuk $m \geq 3$ adalah suatu graf yang mempunyai $2 m+1$ titik yang diperoleh dengan cara menambahkan satu titik untuk setiap jari-jari pada graf roda $W_{m}$.

Berdasarkan Definisi 2.1 maka didefinisikan graf $B W_{3, m}$, untuk $m \geq 3$ sebagai suatu graf dengan $4 m+1$ titik yang diperoleh dengan menambahkan dua titik untuk setiap jari-jari pada graf roda $W_{m}$, untuk $m \geq 3$.

Graf $B W_{2,4}$ dan graf $B W_{3,4}$ diberikan pada Gambar 1 .

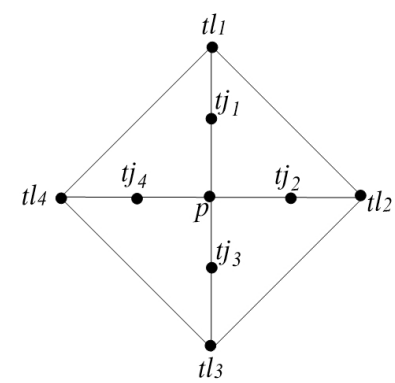

(a)

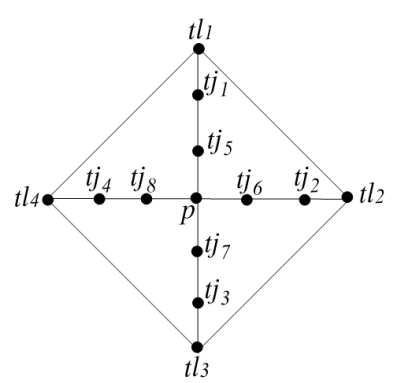

(b)

Gambar 1. Graf Beaded Wheel (a) $B W_{2,4}$ dan (b) $B W_{3,4}$

\section{Bilangan Strong Rainbow Connection untuk NNB$W_{2,4}$ dan $B W_{3,4}$}

Pada penelitian ini didefinisikan $p$ menyatakan titik pusat, $t j$ menyatakan titik jarijari, dan $t l$ menyatakan titik lingkaran. Selanjutnya, didefinisikan letak titik pada graf $B W_{2,4}$ dan $B W_{3,4}$ ditunjukkan seperti pada Gambar 1 sebelumnya.

Teorema 3.1. $\diamond$ Misalkan terdapat graf Beaded Wheel $\left(B W_{2,4}\right)$, maka $\operatorname{src}\left(B W_{2,4}\right)=4$.

Bukti. Akan ditunjukkan bahwa $\operatorname{src}\left(B W_{2,4}\right) \leq 4$. Didefinisikan cara pewarnaan 
pada sisi-sisi $B W_{2,4}$ sebagai berikut.

$$
c(e)= \begin{cases}i, & \text { jika } e=p t j_{i}, \quad 1 \leq i \leq 4 \\ s+1, & \text { jika } e=t j_{s} t l_{s}, \quad 1 \leq s \leq 3 \\ 1, & \text { jika } e=t j_{4} t l_{4}, \\ s, & \text { jika } e=t l_{s} t l_{s+1}, \quad 1 \leq s \leq 3 \\ 4, & \text { jika } e=t l_{4} t l_{1} .\end{cases}
$$

Perhatikan beberapa kasus berikut.

Kasus 1: Pewarnaan pada sisi-sisi subgraf bintang $p t j_{i}$, untuk $1 \leq i \leq 4$.

Subkasus 1.

Misalkan semua sisi $p t j_{i}$ diberikan warna yang sama untuk $1 \leq i \leq 4$. Maka terdapat suatu lintasan $t j_{i}-t j_{j}$ dimana $i \neq j$ untuk $i, j=1,2,3,4$ yang tidak memuat rainbow $u$-v geodesic, sedangkan lintasan tersebut merupakan lintasan dengan panjang $d\left(t j_{i}, t j_{j}\right)$. Oleh karena itu, tidak cukup diberikan satu warna saja.

\section{Subkasus 2.}

Misalkan terdapat sisi $p t j_{i}$ dan $p t j_{j}$ dimana $i \neq j$ untuk $i, j=1,2,3,4$ dengan warna yang sama. Maka lintasan antara $t j_{i}-t j_{j}$ bukan lintasan rainbow $u$-v geodesic, sedangkan lintasan $t j_{i}-t j_{j}$ merupakan satu-satunya lintasan dengan panjang $d\left(t j_{i}, t j_{j}\right)$. Oleh karena itu, tidak cukup diberikan dua warna saja.

Dari Subkasus (1) dan Subkasus (2) diperoleh bahwa setiap sisi $p t j_{i}$, dengan $1 \leq i \leq 4$ harus diwarnai dengan warna yang berbeda:

$$
c(e)=i, e=p t j_{i}, \text { untuk } 1 \leq i \leq 4 .
$$

Kasus 2: Pewarnaan pada sisi-sisi $t j_{i} t l_{i}, 1 \leq i \leq 4$.

Perhatikan bahwa, sisi-sisi $t j_{i}$ tidak boleh diwarnai sama dengan sisi-sisi $p t j_{i}$, untuk $1 \leq i \leq 4$. Jika diwarnai dengan warna yang sama, maka lintasan $t l_{i}-p t j_{i}$ tidak memuat rainbow $t l_{i}-p t j_{i}$ geodesic sedangkan lintasan tersebut mempunyai panjang $d\left(t j_{i}, t l_{i}\right)$. Oleh sebab itu, haruslah $c\left(t j_{i} t l_{i}\right) \neq c\left(p t j_{i}\right)$. Salah satu pewarnaan sisi $t j_{i} t l_{i}$ didefinisikan sebagai berikut.

$$
c(e)= \begin{cases}s+1, & \text { jika } e=t j_{q} t l_{q}, 1 \leq q \leq 3, \\ 1, & \text { jika } e=t j_{4} t l_{4} .\end{cases}
$$

Kasus 3: Pewarnaan pada sisi lingkaran $t l_{i} t l_{i+1}, 1 \leq i \leq 3$ dan sisi $t l_{4} t l_{1}$.

Perhatikan bahwa untuk $1 \leq i \leq 2$ jika $c\left(t j_{i} t l_{i}\right)=i+1$ dan $c\left(t j_{i+1} t l_{i+1}\right)=i+2$ maka haruslah $c\left(t l_{i} t l_{i+1}\right) \neq i+1$ atau $c\left(t l_{i} t l_{i+1}\right) \neq i+2$.

Misalkan $c\left(t l_{i} t l_{i+1}\right)=i+1$, maka lintasan $t j_{i}-t l_{i+1}$ tidak memuat rainbow $t j_{i}-t l_{i+1}$ geodesic, sedangkan lintasan tersebut satu-satunya lintasan dengan panjang $d\left(t j_{i}, t l_{i+1}\right)$ yang menghubungkan titik-titik tersebut, sehingga haruslah $c\left(t l_{i} t l_{i+1}\right) \neq i+1$. Selanjutnya, misalkan $c\left(t l_{i} t l_{i+1}\right)=i+2$ maka, lintasan $t l_{i}-t j_{i+1}$ tidak memuat rainbow $t j_{i}-t l_{i+1}$ geodesic, sedangkan lintasan tersebut merupakan lintasan yang pajangnya $d\left(t j_{i}, t l_{i+1}\right)$, sehingga haruslah $c\left(t l_{i} t l_{i+1}\right) \neq i+2$.

Selanjutnya, jika $c\left(t j_{3} t l_{3}\right)=4$ dan $c\left(t j_{4} t l_{4}\right)=1$ maka haruslah $c\left(t l_{3} t l_{4}\right) \neq 4$ atau $c\left(t l_{3} t l_{4}\right) \neq 1$. 
Misalkan $c\left(t l_{3} t l_{4}\right)=4$ maka lintasan $t j_{3}-t l_{4}$ tidak memuat rainbow $t j_{3}-$ $t l_{4}$ geodesic, sedangkan lintasan tersebut sepanjang $d\left(t j_{3}, t l_{4}\right)$, sehingga haruslah $c\left(t l_{3} t l_{4}\right) \neq 4$. Selanjutnya misalkan $c\left(t l_{3} t l_{4}\right)=1$ maka, lintasan $t j_{4}-t l_{3}$ tidak memuat rainbow $t j_{3}-t l_{4}$ geodesic, sehingga haruslah $c\left(t l_{3} t l_{4}\right) \neq 1$. Sama halnya dengan konsep pewarnaan sebelumnya, maka haruslah $c\left(t l_{4} t l_{1}\right) \neq 1$ atau $c\left(t l_{4} t l_{1}\right) \neq$ 2. Salah satu definisi pewarnaannya sebagai berikut.

$$
c(e)=\left\{\begin{array}{l}
s, \text { jika } e=t l_{s} t l_{s+1}, 1 \leq s \leq 3, \\
4, \text { jika } e=t l_{4} t l_{1} .
\end{array}\right.
$$

Berdasarkan ketiga kasus tersebut diperoleh bahwa, untuk setiap dua titik $u, v$ di $B W_{2,4}$ selalu terdapat lintasan dengan panjang $d(u, v)$ yang merupakan lintasan rainbow geodesic. Sehingga diperoleh bahwa $\operatorname{src}\left(B W_{2,4}\right) \leq 4$.

Selanjutnya akan ditunjukkan batas bawah dari $\operatorname{src}\left(B W_{2,4}\right)$, yaitu $\operatorname{src}\left(B W_{2,4}\right) \geq$ 4. Misalkan $\operatorname{src}\left(B W_{2,4}\right) \leq 3$, maka minimal banyak warna yang dibutuhkan untuk membuat setiap lintasan dengan panjang $d(u, v)$ memuat rainbow $u$-v geodesic, yaitu 3 coloring. Berdasarkan Kasus (1), maka banyak warna yang dibutuhkan untuk mewarnai sisi-sisi pada subgraf bintang $p t j_{i}$ agar lintasan $t j_{i}-t j_{j}$ untuk $i \neq j$ memuat rainbow u-v geodesic, haruslah sebanyak 4-coloring. Akibatnya kontradiksi dengan pemisalan sebelumnya, maka diperoleh haruslah $\operatorname{src}\left(B W_{2,4}\right) \geq 4$.

Berdasarkan kasus-kasus di atas, terbukti bahwa $\operatorname{src}\left(B W_{2,4}\right) \leq 4$ dan $\operatorname{src}\left(B W_{2,4}\right) \geq 4$. Sehingga diperoleh $\operatorname{src}\left(B W_{2,4}\right)=4$.

Teorema 3.2. $\diamond$ Misalkan terdapat graf Beaded Wheel $B W_{3,4}$, maka $\operatorname{src}\left(B W_{3,4}\right)=$ 5 .

Bukti. Pertama akan ditunjukkan bahwa $\operatorname{src}\left(B W_{3,4}\right) \leq 5$. Definisikan cara pewarnaan pada sisi-sisi $B W_{3,4}$ sebagai berikut,

$$
c(e)= \begin{cases}i, & \text { jika } e=p t j_{4+i}, \quad 1 \leq i \leq 4, \\ 5, & \text { jika } e=t j_{4+q} t j_{q}, \quad 1 \leq q \leq 4, \\ s+1, & \text { jika } e=t j_{s} t l_{s}, \quad 1 \leq s \leq 3, \\ 1, & \text { jika } e=t j_{4} t l_{4} . i, \quad \text { jika } e=t l_{i} t l_{i+1}, 1 \leq i \leq 3, \\ 4, & \text { jika } e=t l_{4} t l_{1} .\end{cases}
$$

Perhatikan beberapa kasus sebagai berikut.

Kasus 1: Pewarnaan pada sisi-sisi subgraf bintang $k=p t j_{4+i}, 1 \leq i \leq 4$

Berdasarkan pembuktian Teorema 3.1 Kasus (1), diperoleh bahwa sisi-sisi $k$ haruslah diberi sebanyak $k$ warna, yaitu

$$
c(e)=i, \text { jika } e=p t j_{4+i}, \text { untuk } 1 \leq i \leq 4 .
$$

Dengan pewarnaan tersebut, lintasan $t j_{4+i^{-}} t j_{4+j}$ dimana $i \neq j$ untuk $i, j=$ 1,2,3,4 merupakan lintasan dengan panjang $d\left(t j_{4+i}, t j_{4+j}\right)$ yang memuat rainbow $t j_{4+i}, t j_{4+j}$ geodesic.

Kasus 2: Pewarnaan pada sisi-sisi $s=t j_{4+i} t j_{i}, 1 \leq i \leq 4$.

Misalkan pewarnaan $k$ didefinisikan $k_{i}=c\left(p t j_{i}\right)$, dan $s$ didefinisikan $s_{i}=c\left(t j_{4+i} t j_{i}\right)$, 
maka haruslah $k_{j} \neq s_{i}$. Misalkan $k_{j}=s_{i}$ maka pada lintasan dimana setiap dua titik yang dimulai dari titik $t j_{i}$ ke titik yang melewati sisi subgraf bintangnya tidak akan memuat rainbow $u-v$ geodesic, sedangkan lintasan tersebut mempunyai panjang $d(u, v)$. Sehingga satu-satunya cara untuk mewarnai sisi-sisi $s$ yaitu, setiap sisinya diberikan warna yang berbeda dari warna sisi-sisi pada $k$. Adapun cara mewarnainya didefinisikan sebagai berikut.

$$
c(e)=4+1 \text {, jika } e=t j_{4+q} t j_{q}, \text { untuk } 1 \leq q \leq 4 .
$$

Kasus 3: Pewarnaan pada sisi-sisi $u=t j_{i} t l_{i}, 1 \leq i \leq 4$

Misalkan pewarnaan $u$ didefinsikan $u_{i}=c\left(t j_{i} t l_{i}\right)$ dan pewarnaan $k$ didefinisikan $k_{i}=c\left(p t j_{i}\right)$. Berdasarkan pembuktian Teorema 3.1 kasus (2), maka haruslah $u_{i} \neq k_{i}$ agar lintasan $t l_{i}-p$ memuat rainbow $u$ - $v$ geodesic. Salah satu definisi pewarnaannya adalah:

$$
c(e)= \begin{cases}s+1, & \text { jika } e=t j_{s} t l_{s}, 1 \leq s \leq 3, \\ 1, & \text { jika } e=t j_{4} t l_{4} .\end{cases}
$$

Kasus 4: Pewarnaan pada sisi-sisi $z=t l_{i} t l_{i+1}$, untuk $1 \leq i \leq 3$ dan sisi $t l_{4} t l_{1}$ Berdasarkan pembuktian Teorema 3.1 kasus (3), maka sisi-sisi $z$ diberikan 4 warna, sementara untuk $1 \leq i \leq 2$ :

$$
\begin{array}{rll}
c\left(t l_{i} t l_{i+1}\right) \neq i+1 & \text { atau } & c\left(t l_{i} t l_{i+1}\right) \neq i+2, \\
c\left(t l_{3} t l_{4}\right) \neq m \text { atau } & c\left(t l_{3} t l_{4}\right) \neq 1, \\
c\left(t l_{4} t l_{1}\right) \neq 1 \text { atau } & c\left(t l_{4} t l_{1}\right) \neq 2 .
\end{array}
$$

Selanjutnya, untuk $1 \leq i \leq 4$ terdapat pewarnaan $c\left(t j_{4+i} t l_{i}\right)=4+1$, maka untuk $1 \leq i \leq 3$, sisi $t l_{i} t l_{i+1}$ dan $t l_{4} t l_{1}$ tidak boleh diwarnai dengan warna 5 . Misalkan sisi-sisi tersebut diwarnai dengan warna 5 maka untuk $m=4$, lintasan $t l_{1}-t j_{6}, t l_{2}-$ $t j_{7}, t l_{3}-t j_{8}$ dan $t l_{4}-t j_{5}$ bukan lintasan rainbow geodesic. Oleh karena itu, haruslah sisi- sisi $t l_{i} t l_{i+1}$ dan $t l_{4} t l_{1}$ tidak diwarnai dengan warna 5 . Berdasarkan kasus di atas, maka salah satu definisi pewarnaan sebagai berikut,

$$
c(e)= \begin{cases}i, & \text { jika } e=t l_{i} t l_{i+1}, 1 \leq i \leq 3, \\ 4, & \text { jika } e=t l_{4} t l_{1} .\end{cases}
$$

Berdasarkan Kasus (1), (2), (3) dan (4), diperoleh bahwa untuk setiap dua titik $u$ dan $v$ di $B W_{3,4}$, selalu terdapat lintasan dengan panjang $d(u, v)$ yang mrupakan lintasan rainbow geodesic. Sehingga diperoleh $\operatorname{src}\left(B W_{3,4}\right) \leq 5$.

Selanjutnya akan ditunjukkan batas bawah dari $\operatorname{src}\left(B W_{3,4}\right)$, yaitu $\operatorname{src}\left(B W_{3,4}\right) \geq$ 5. Misalkan $\operatorname{src}\left(B W_{3,4}\right)<5$, yaitu 4 , maka minimal banyak warna yang dibutuhkan untuk membuat setiap lintasan dengan panjang $d(u, v)$ memuat rainbow $u-v$ geodesic, yaitu 4 coloring. Akan tetapi, berdasarkan Kasus (2) diperoleh bahwa banyak warna yang dibutuhkan untuk setiap dua titik yang dimulai dari $t j_{i}$ ke titik yang melintasi sisi subgraf bintangnya, tidak cukup untuk membuat lintasan tersebut memuat rainbow $u$-v geodesic. Oleh sebab itu diperlukan warna tambahan, yang didefinisikan sebagai

$$
c(e)=5, \text { jika } e=t j_{4+q} t j_{q}, \text { untuk } 1 \leq q \leq 4 .
$$


Ini kontradiksi dengan pemisalan sebelumnya bahwa $\operatorname{src}\left(B W_{3,4}\right)<5$, sehingga haruslah $\operatorname{src}\left(B W_{3,4}\right) \geq 5$.

Berdasarkan kasus-kasus di atas, terbukti $\operatorname{src}\left(B W_{3,4}\right) \leq 5$ dan $\operatorname{src}\left(B W_{3,4}\right) \geq 5$. Sehingga diperoleh $\operatorname{src}\left(B W_{3,4}\right)=5$.

\section{Daftar Pustaka}

[1] Ali, K., E.T. Baskoro dan I. Tomescu. 2009. On the Ramsey Number For Paths and Beaded Wheel. Journal of Prime Research in Mathematics 5: 133 - 138

[2] Chartrand, G. dan P. Zhang. 2005. Introduction to Graph Theory. Mc-Graw Hill. International Edition. Singapore

[3] Chartrand, G., G.L Johns, K.A. McKeon, P. Zhang, Rainbow Connection in Graphs, Math. Bohem. $133: 85-98$

[4] Reinhard, D. 2000. Graph Theory. Graduate Texts in Mathematics. 2 ${ }^{\text {ed }}$, Springer: New York.

[5] Sy, S., G. Histamedika dan L. Yulianti. 2013. The Rainbow Connection Of Fan and Sun, Applied Mathematical Science $7: 3155$ - 3159.

[6] X. Li dan Y. Sun. 2013. On Strong Rainbow Connection Number of a Graph, Bull. Malays. Math. Sci. Soc (2) 36 (2): 299 - 311 